\title{
Rational Use of Fungicide Applications to Maximize Peanut Yield Under Foliar Disease Pressure in West Africa
}

\author{
F. Waliyar, Principal Plant Pathologist, ICRISAT, B. P. 320 Bamako, Mali; Moustapha Adamou, Agronomist, \\ INRAB, B. P. 884, Cotonou, Benin; and Aoua Traoré, Research Assistant, ICRISAT, B. P. 320 Bamako, Mali
}

\begin{abstract}
Waliyar, F., Adamou, M., and Traoré, A. 2000. Rational use of fungicide applications to maximize peanut yield under foliar disease pressure in West Africa. Plant Dis. 84:1203-1211.

Foliar diseases caused by Cercospora arachidicola, Cercosporium personatum, and Puccinia arachidis are major constraints to peanut production in the world. Fungicides are among the most efficient available control methods. Field trials were conducted in 1991 and 1992 in Benin and Niger, West Africa, to evaluate the cost effectiveness of fungicide application timings and frequencies on four peanut cultivars. A combination of four timings (40, 55, 70, and 85 days after sowing) was scheduled. Early (causal organism, C. arachidicola) and late (caused by C. personatum) leaf spot were prevalent in both years, but late leaf spot was the more economically important disease as shown by high values of area under the disease progress curve. Application of fungicide reduced late leaf spot incidence and increased pod yield. Pod yield responded to an interaction of number and timing of fungicide applications. With appropriate timing two or three fungicide applications were enough to significantly increase pod yield. Properly timed fungicide sprays can result in substantial monetary gains for peanut farmers in West Africa.
\end{abstract}

Additional keywords: Arachis hypogaea

In West and Central Africa, three foliar diseases-early leaf spot caused by Cercospora arachidicola $\mathrm{S}$. Hori; late leaf spot caused by Cercosporidium personatum Berk. \& M.A. Curtis (syn. Phaeoisariopsis personata (Berk. \& M.A. Curtis) Arx); and rust caused by Puccinia arachidis Speg.are major constraints to peanut production. Disease distribution and severity vary from region to region with yield losses ranging from 10 to $50 \%$ depending on the agroecological zone and cultivar $(7,15,21,22)$. While the mean pod yield in West Africa is about $750 \mathrm{~kg} / \mathrm{ha}$, data from the region show that some cultivars produce much higher yields when protected from foliar diseases. At present, only a few cultivars are partially resistant to foliar diseases. Fungicides are used currently in some regions of Africa $(11,18)$, but several applications are applied to prevent disease. This approach is expensive and therefore not accessible to most farmers. However, a limited number of fungicide applications could substantially increase pod yield. To reduce the number of fungicide applications, approaches such as disease prediction models for alerting farmers to spray have been

Corresponding author: F. Waliyar

E-mail: f.waliyar@icrisatml.org

Accepted for publication 24 July 2000.

Publication no. D-2000-0919-01R

(c) 2000 The American Phytopathological Society developed (2). Our objectives were to identify the best combination of timing and number of fungicide applications in relation to cultivars to achieve best pod yield. This article describes results obtained from Bengou (Niger) and Ina (Benin) in the 1991 and 1992 rainy seasons.

\section{MATERIALS AND METHODS}

The trial was conducted at Bengou (Niger) and Ina (Benin) in the 1991 and 1992 rainy seasons. Bengou is located in southwest Niger ( $3^{\circ} 30^{\prime}$ east longitude, $11^{\circ} 59^{\prime}$ north latitude, $160 \mathrm{~m}$ altitude). Mean rainfall from May to October is 786 $\mathrm{mm}$ and soil is classified as sandy, siliceous, isohyperthermic, psammentic, Paleustalf with $0.7 \%$ organic matter and 1.9 to
$3.5 \%$ clay. Ina is located in southern Benin at $2^{\circ} 44^{\prime}$ east longitude, $9^{\circ} 58^{\prime}$ north latitude, $358 \mathrm{~m}$ altitude. Mean rainfall from May to October is $1,000 \mathrm{~mm}$. The ferruginous tropical soils are characterized by hydromorph concretion and shallow and clayeymuddy texture.

Four peanut cultivars (55-437, 47-16, ICGS 11, and 28-206) were evaluated in both locations. Cultivar 55-437 is an early maturing ( $<100$ days) Spanish type widely grown in the semi-arid zone of West Africa; cv. 47-16 is a Virginia runner and cv. 28-206 is a Virginia bunch type. Both are late maturing (>120 days); cv. ICGS 11 is a Spanish bunch type of medium maturing, high yielding line developed by ICRISAT.

The experimental design was a split-plot with 16 fungicide spray treatments applied to main plots and four peanut lines planted in subplots. There were three replications. Fungicide was applied at 40, 55, 70, and 85 days after sowing (DAS). (Table 1). The fungicide used was Corvet CM (fenpropimorphe [18.8\%], mancozeb [40.0\%], carbendazim [5.0\%]) at the rate of $2 \mathrm{~kg} / \mathrm{ha}$ of commercial product.

Each plot was 4 rows $\times 6 \mathrm{~m}$ long with spacing of $10 \mathrm{~cm}$ between plants and 50 $\mathrm{cm}$ between the rows. Before planting, fields were prepared using animal drawn plows and $40 \mathrm{~kg} / \mathrm{ha}$ of $\mathrm{P}_{2} \mathrm{O}_{5}$ were broadcast. Seeds were treated with Thioral $(25 \%$ heptachlore and $25 \%$ thiram) at a rate of 3 $\mathrm{g} / \mathrm{kg}$ of seed. During the cropping season plots were weeded twice using hand hoes.

Disease severity (percentage of leaflets infected) and percent defoliation (on the main stem) were recorded prior to each fungicide application at an interval of 15

Table 1. Time of fungicide application in days after sowing (DAS)

\begin{tabular}{lcccc}
\hline Treatment & 40 DAS & 55 DAS & 70 DAS & 85 DAS \\
\hline 1 none & & & & \\
2 single & $\mathrm{X}$ & $\mathrm{X}$ & & \\
3 & & & $\mathrm{X}$ & \\
4 & & $\mathrm{X}$ & $\mathrm{X}$ \\
5 & $\mathrm{X}$ & $\mathrm{X}$ & \\
6 double & $\mathrm{X}$ & $\mathrm{X}$ & $\mathrm{X}$ & $\mathrm{X}$ \\
7 & $\mathrm{X}$ & $\mathrm{X}$ & $\mathrm{X}$ & $\mathrm{X}$ \\
8 & & $\mathrm{X}$ & $\mathrm{X}$ & $\mathrm{X}$ \\
9 & & $\mathrm{X}$ & $\mathrm{X}$ & $\mathrm{X}$ \\
10 & $\mathrm{X}$ & $\mathrm{X}$ & $\mathrm{X}$ & $\mathrm{X}$ \\
11 & $\mathrm{X}$ & $\mathrm{X}$ & $\mathrm{X}$ & $\mathrm{X}$ \\
12 triple & $\mathrm{X}$ & & & \\
13 & $\mathrm{X}$ & & & \\
15 & & & & \\
16 quadruple & & & & \\
\hline
\end{tabular}


days between each treatment. Plants were harvested according to their maturity. At harvest, pod and haulm yields and shelling percentage were measured. Area under the disease progress curve (AUDPC) was calculated as described by Shaner and Finney (19).

Economic evaluation of fungicide treatment options-Conceptual framework. We assumed that farmers want to maximize satisfaction from expected net gains to investments on their farms. They choose among the most risk efficient fungicide treatments. In this article, the conceptual criterion for making efficient choices based on expected utility is the mean-standard deviation framework frequently used in portfolio analysis. In agriculture, portfolio analysis is used to help farmers make production decisions (e.g., acreage planning decisions, fungicide treatment options), financial, or marketing decisions or a combination of the above. Portfolio analysis also is used to help policymakers predict farmers' responses to policy decisions or extension agents select the best technological packages with the best chance of adoption by farmers.

The ranking of risky choices in an expected utility framework context depends on the way in which uncertainty is measured. In this study, the standard deviation of net gains will be used as a proxy for risk or uncertainty. This assumes that the distribution of net gains for all alternative fungicide treatment options is multivariate normal (the mean and covariance-matrix are the two basic statistics of the distribution of net gains) and the correlation between alternative fungicide treatments is not significant. The mean and the standard deviation are the main statistics used to rank alternative treatment options. We assumed that farmers are averse to risk. If farmers are given two choices that have the same mean, farmers will prefer choices with the smaller standard deviation or risk. Similarly, for two choices with the same standard deviation or risk, farmers will prefer the choice with higher mean. In general, given a set of admissible options, we have to search for an efficient set of decisions in the sense that decisions in the set are undominated based on the mean and standard deviation and thus admissible to farmers adverse to risk $(1,3,8,12)$. The graphical approach of mean-standard deviation consists of mapping choices in a mean-standard deviation setting and selecting only undominated choices.

Net gains were calculated for each spray treatment on a marginal benefits basis. Gross returns for each treatment were calculated by multiplying yield by the average farm-gate prices of peanut following harvest (estimated at $300 \mathrm{CFA}$ francs/kg; 585 CFA francs or F CFA equal to \$U.S. 1). The cost of fungicide application has three components: the actual cost of fungicide; labor cost for spraying; and rental cost of spraying equipment. Fungicide cost was estimated at 16,000 F CFA/ha, labor cost at 1,368 F CFA/ha, and equipment rental at 4,000 F CFA/ha. The total costs were assumed to be a linear function of number of sprays. The net gain per hectare of each treatment was calculated by subtracting the net returns of the control treatment (no fungicide application) from the net returns of each treatment.

In this study, two scenarios were considered depending on whether farmers are resource-constrained or not. In the first scenario, it was assumed that farmers are not resource or credit constrained and would choose among the best combinations of fungicide application frequencies and date of application based on peanut variety. In the second scenario, we assumed that farmers have no access to credit and farmers' choice is contingent upon their level of resource endowments. In effect, if farmers have resources sufficient to undertake only one fungicide treatment or one spray, we wanted to determine what would be the best the timing of application based on variety.

\section{RESULTS}

Early and late leaf spot were present at both locations. When fungicide was not applied, low levels of early leaf spot were observed between 40 and 55 DAS. Late leaf spot appeared between 50 and 60 DAS and progressed very rapidly, whereas early leaf spot progressed no further. In both years and at both locations, $100 \%$ leaf area was damaged at the end of the season when fungicides were not applied. Disease progressed faster in early maturing cultivars than in medium maturing ones.

Effect of fungicide on disease at Bengou, Niger. Late leaf spot was more severe in 1992 (Fig. 1E-H) than in 1991 (Fig. 1A-D) based on AUDPC values. The highest AUDPC was observed with the short duration susceptible cultivar 55-437 in 1992 (Fig. 1E). The leaf area damage was estimated at $99 \%( \pm 4.1)$.

Fungicide application suppressed disease in most treatments but the magnitude of this reduction depended on cultivars and number and timing of fungicide applications. One fungicide spray applied at 40 , 55 , or 70 DAS significantly reduced AUDPC values from those observed in unsprayed treatments (Fig. 1A-H). The application of one spray at 85 DAS did not reduce disease severity compared with the unsprayed control.

Two spray applications (treatment 6 to 11) significantly reduced disease (lower AUDPC) compared with the unsprayed treatment, although some combinations of spray dates were more effective than others. For example, for the short duration cultivar 55-437, an early spray 40 DAS combined with second spray at 55 DAS (treatment 6) or at 70 DAS (treatment 7) was more effective than at 40 DAS and 85
DAS (treatment 8). The same trend was observed with sprays at 55 and 70 DAS (treatment 9). This combination appeared to be effective in both years and for all genotypes in Niger.

With the application of three sprays, AUDPC values were significantly lower than those for one or two sprays independent of spray date. The best response was found when three fungicide applications were made at 40,55 , and 70 DAS.

The AUDPC values were lowest when four fungicide applications were made, except in the case of cultivars 47-16, ICGS 11, and 28-206 in 1991 (Fig. 1B-D). In these cases, some combinations of three sprays had lower AUDPC values than did four spray combinations.

Effect of fungicide on disease at Ina, Benin. Cultivar 55-437 was the most susceptible, with 96 and $99 \%( \pm 4.9)$ leaf area damage, respectively, in 1991 and 1992. Late leaf spot disease was very severe in both years. The AUDPC values were higher in Benin than in Niger. These values varied from 900 to more than 3,000 depending on the genotype and combination of fungicide sprays (Fig. 2A-H). The final disease severity in these treatments ranged from 43 to $99 \%$ in Benin and from 9 to $99 \%$ in Niger.

For all genotypes, the application of one fungicide spray at 55 DAS (treatment 3) controlled late leaf spot more effectively than any other single application date. The last application (85 DAS) did not have any effect on foliar disease development.

With two sprays, AUDPC values were high and not significantly less than those for one or no spray treatments except for treatment 9 (combination of 55 and 70 DAS). In a few cases treatment 6 (40 and 55 DAS) also reduced foliar disease.

When three fungicide applications were used, the AUDPC values were lower, but timings differed between 1991 and 1992. In 1991 (Fig. 2A-D), the best combination began later $(55,70$, and 85 DAS) whereas in 1992 (Fig. 2E-H) the best response was obtained when the first application was given early (40, 55, and 70 DAS). The application of four sprays significantly reduced foliar disease at Bengou in most cultivars in both years.

Effect of fungicide on pod yield at Bengou, Niger. An increase in the number of fungicide applications resulted in increased pod and haulm yields in all genotypes in both years. Higher mean yields were obtained at Bengou (Niger) than at Ina (Benin). Cultivar 55-437 produced 3.11 t/ha $( \pm 0.11)$ in 1991 and 2.53 t/ha $( \pm 0.12)$ in 1992 at Bengou. Average yields at Ina were $1.64 \mathrm{t} / \mathrm{ha}( \pm 0.11)$ in 1991 and 1.53 $\mathrm{t} / \mathrm{ha}( \pm 0.09)$ in 1992. In the absence of fungicide protection, ICGS 11 was most productive in both locations and years.

At Bengou, one spray increased pod yield but the increase depended on genotype and timing. For the early genotype 

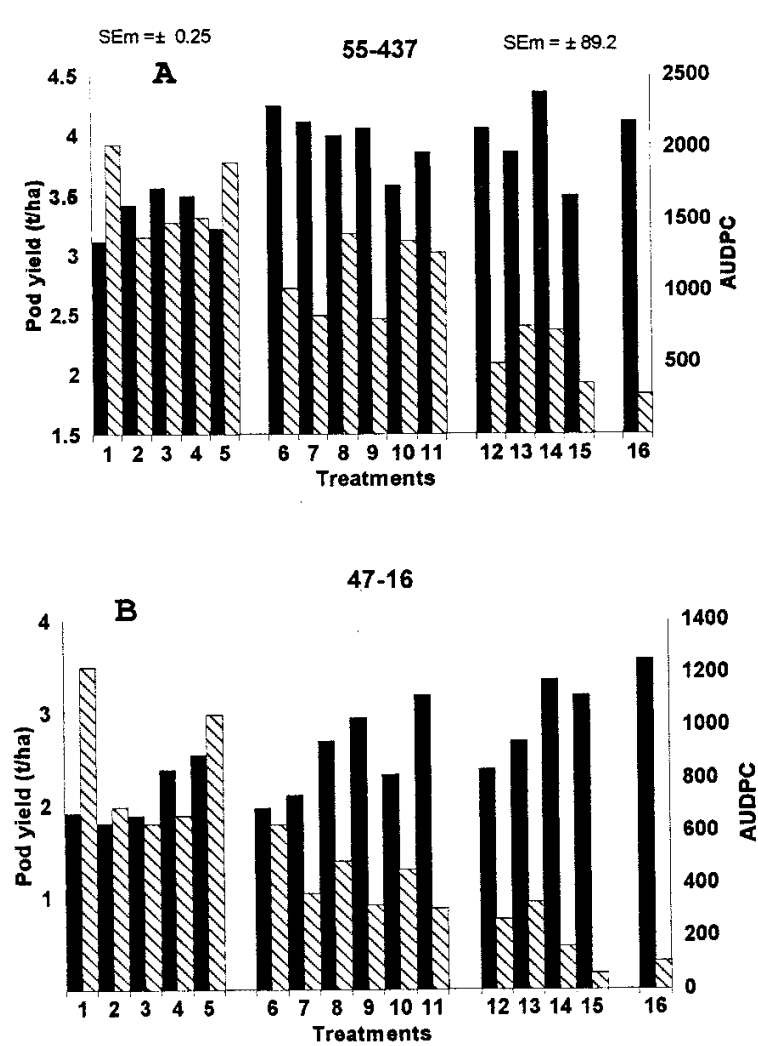

28-206

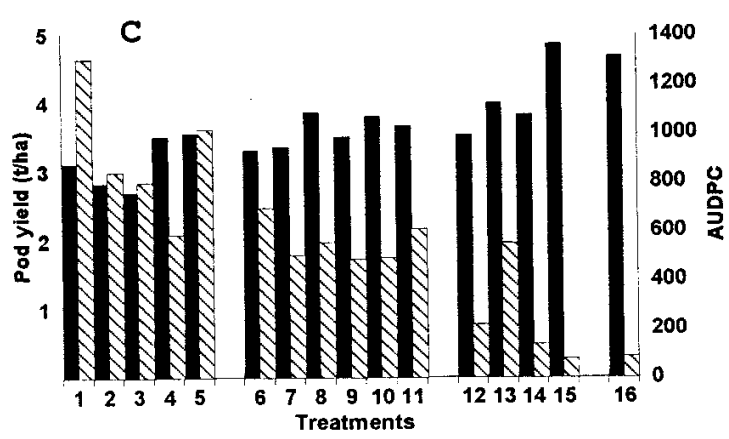

ICGS11

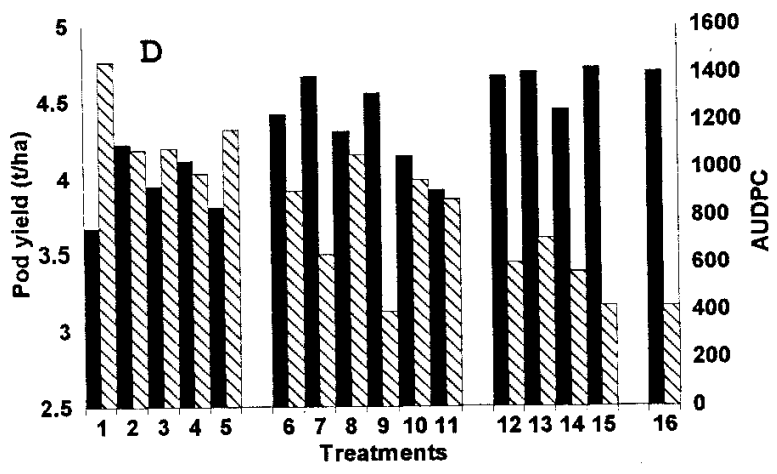

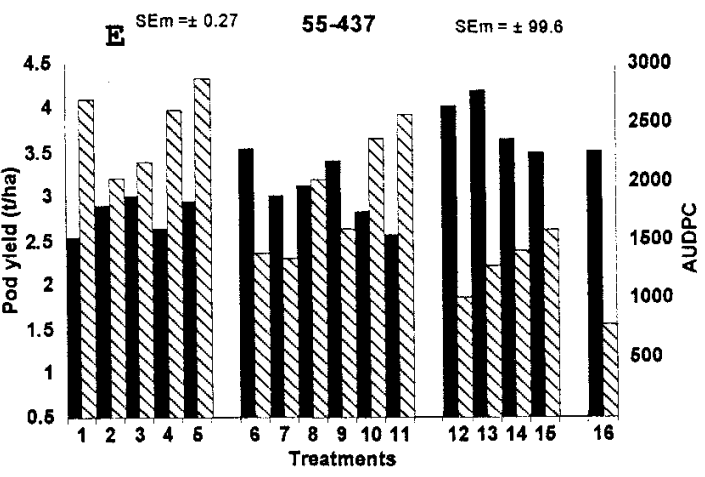

47-16

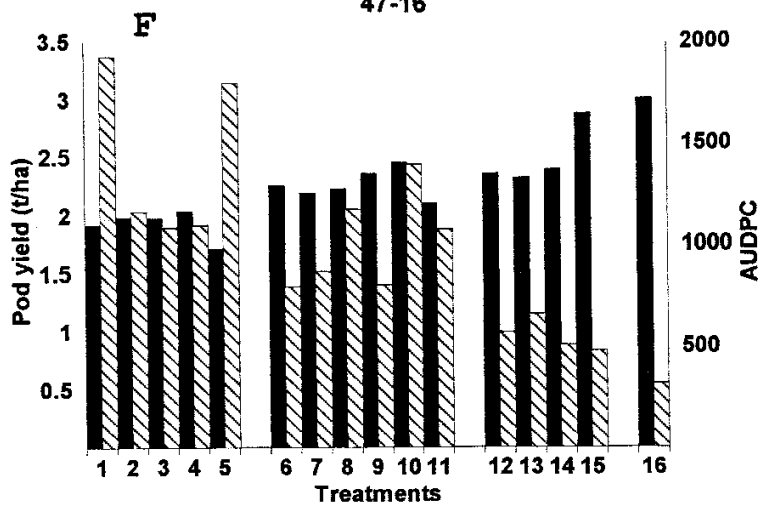

28-206

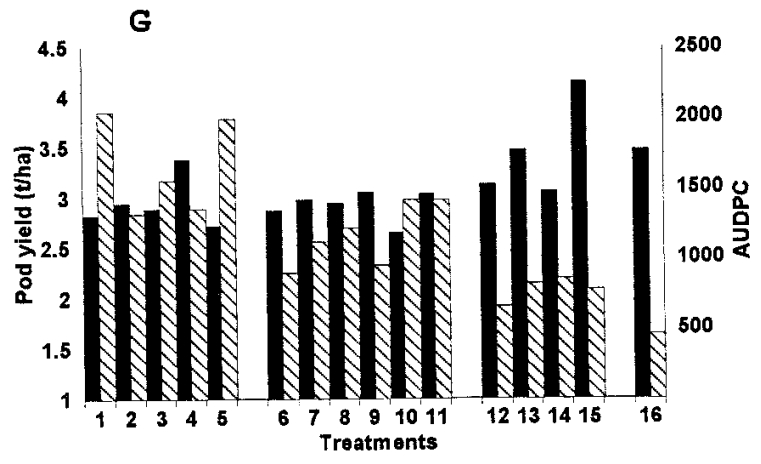

ICGS11

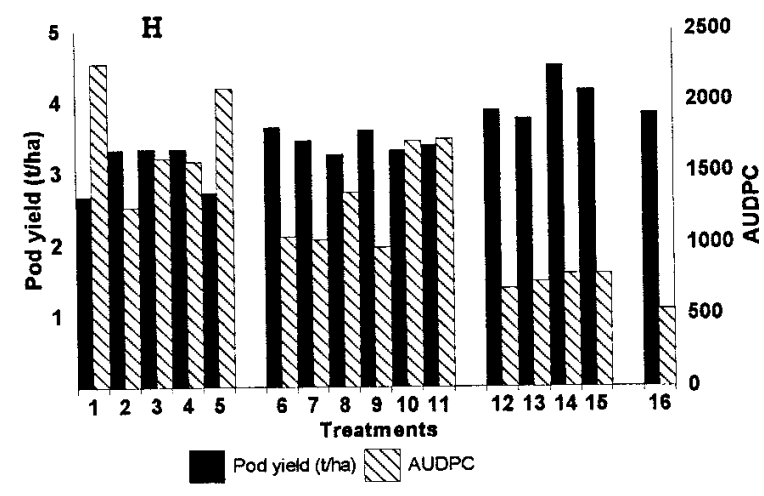

Fig. 1. Pod yield and late leaf spot severity (expressed as area under disease progress curve [AUDPC]) in four peanut cultivars grown in Bengou, Niger, in 1991 (A-D) and 1992 (E-H). Treatments: $1=$ none; $2=40$ days after sowing (DAS); $3=55$ DAS; $4=70$ DAS; $5=85$ DAS; $6=40$ and 55 DAS; $7=40$ and 70 DAS; $8=40$ and 85 DAS; $9=55$ and 70 DAS; $10=55$ and 85 DAS; $11=70$ and 85 DAS; $12=40,55$, and 70 DAS; $13=40,55$, and 85 DAS; 14 $=40,70$, and 85 DAS; $15=44,70$, and 85 DAS; and $16=40,55,70$, and 85 DAS. 

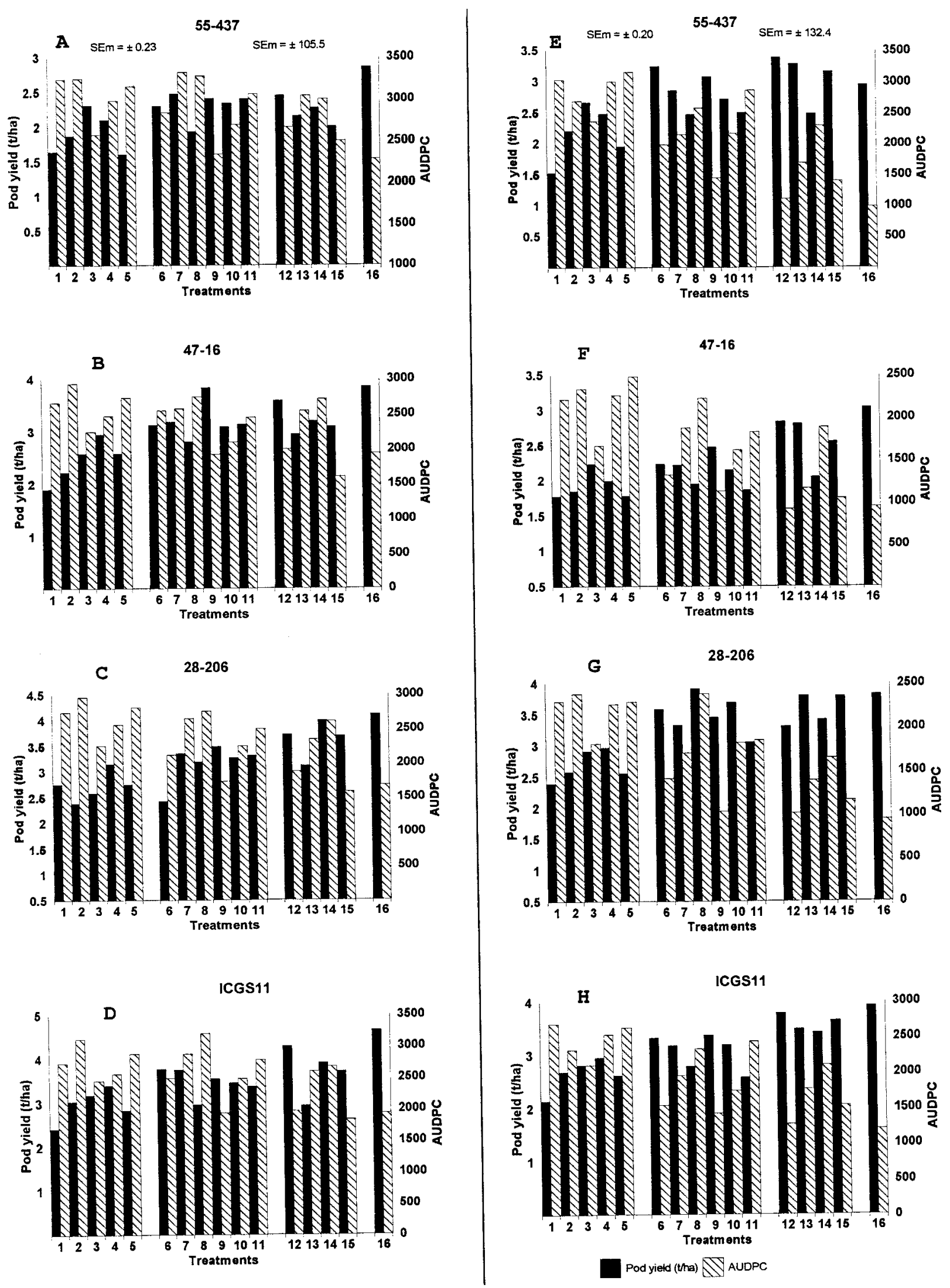

Fig. 2. Pod yield and late leaf spot severity (expressed as area under disease progress curve [AUDPC]) in four peanut cultivars grown in Ina, Benin, in 1991 (A-D) and 1992 (E-H). Treatments: $1=$ none; $2=40$ days after sowing (DAS); $3=55$ DAS; $4=70$ DAS; $5=85$ DAS; $6=40$ and 55 DAS; $7=40$ and 70 DAS; $8=40$ and 85 DAS; $9=55$ and 70 DAS; $10=55$ and 85 DAS; $11=70$ and 85 DAS; $12=40,55$, and 70 DAS; $13=40,55$, and 85 DAS; 14 $=40,70$, and 85 DAS; $15=44,70$, and 85 DAS; and $16=40,55,70$, and 85 DAS. 
55-437, one spray at 55 DAS produced higher pod yield than a single spray at any other date. For the medium duration genotypes (28-206 and 47-16), the application of fungicide at 70 or 85 days resulted in higher pod yield. ICGS 11 produced the highest yield in both years even in the absence of fungicide sprays.

With two sprays, the timing of fungicide applications became important. For the short duration line (55-437), the combination of two early sprays was the most effective (treatment 6, Fig. 1A and E). Cultivar 28-206 did not show any significant increase compared to one spray. For genotype ICGS 11, yield increases occurred with fungicide applications at 40 and 70 DAS (treatment 7, Fig. 1D) or 55 and 70 DAS (treatment 9, Fig. 1H). The combination of late sprays produced higher yield for 47-16 than for other cultivars (Fig. 1C and $\mathrm{G})$.

In general, combinations of late sprays significantly enhanced yield of all genotypes with the exception of 55-437 in 1992. For all genotypes, four sprays produced high pod and haulm yields. ICGS11 and 28-206 were most productive; however, various combinations of two or three fungicide sprays were best on these cultivars.

Effect of fungicide on pod yield at Ina, Benin. With no fungicide application, pod yields varied between 1.7 and 2.7 t/ha. With one spray, the pod yield significantly increased, but the increase depended on variety and time of application. Application of fungicide at 55 or 70 DAS in- creased pod yield of most genotypes. Late sprays were more effective on long duration genotypes such as 28-206 and 47-16. Spraying these two lines at 70 DAS produced 3.16 and $2.94 \mathrm{t} / \mathrm{ha}$ of pods, whereas spraying at 40 DAS resulted in yields of 2.38 and $2.22 \mathrm{t} / \mathrm{ha}$, respectively.

With two sprays, pod yield was higher than one or no spray. For most genotypes, treatment 9 (55 and 70 DAS) produced highest yields followed by treatment 6 (40 and 55 DAS).

Mean yields for treatments with three applications were not significantly higher than with two fungicide applications. Nevertheless, some triple combinations produced higher yields on specific genotypes. For 55-437 and ICGS 11, treatment 12 (40, 55 , and 70 DAS) produced the highest yield in both years.

With four fungicide applications, pod yields were high for most genotypes both years. However, some combinations of fewer fungicide applications resulted in equivalent yields, e.g., treatment 9 (Fig. 2C) and treatment 12 (Fig. 2D).

Economic importance of fungicide sprays. The economic importance of fungicide treatments is presented following the two scenarios mentioned. In all cases, application of fungicide increased pod yield of peanut, which in turn depends on variety, time, and number of applications. Similarly, there is a set of risk-efficient fungicide treatment options from which farmers adverse to risk could choose to maximize their expected utility.
First scenario-Farmers are not resource-constrained. Decision trees assist farmers in choosing fungicide application frequencies and dates of application according to peanut varieties (Figs. 3 and 4). For example, for peanut variety 28-206 in Bengou, Niger (Fig. 3), there were 14 admissible cases of which only three options were found undominated according to the mean-standard deviation criterion (Fig. 5). The treatments 40, 55, 70, and 85 DAS and 55 and 70 DAS have about the same risk (about 155,000 F CFA of standard deviation), however, the average net gains of the first $(245,028 \mathrm{~F} \mathrm{CFA})$ is higher than the average net gains of the second (49264 F CFA). According to the mean-standard deviation criterion, the treatment 55 and 70 DAS is dominated by the treatment $40,55,70$, and 85 DAS. Similarly, if one compares the treatments 70 DAS and 40 , 70 , and $85 \mathrm{DAS}$, the former has a higher mean and lower risk than the latter; therefore, the treatment at 70 DAS dominates that of 40,70 , and 85 DAS. Following the same approach, options in the risk efficient set for the variety 28 206 included one fungicide spray 70 DAS; 3 sprays, 55, 70, and 85 DAS; and four sprays. Therefore, farmers could choose to spray at 70 DAS or at 55,70 , and 85 DAS or at $40,55,70$, and 85 days to maximize their utility.

In Niger, depending on variety, frequency of treatments, and dates of application, farmers have two or three options. For most, the highest returns were attained

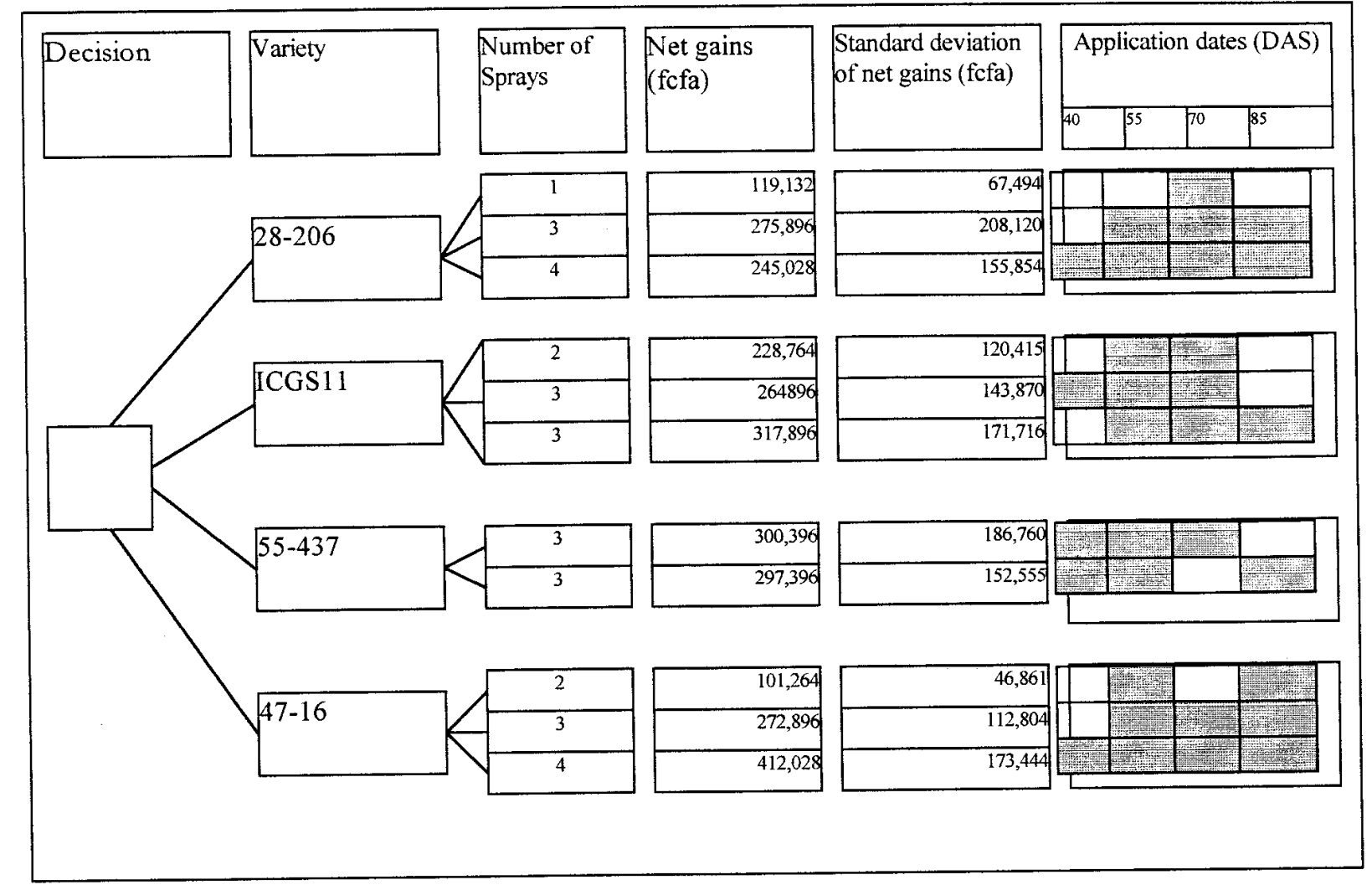

Fig. 3. Decision tree to assist farmers in choosing fungicide application frequencies and dates according to peanut variety in Niger. 
with three sprays, except for the variety 47-16 where the highest returns were attained with four fungicide applications. In general, for late maturing varieties (28-206 or 47-16) fungicide treatments towards the end of the cycle provide the best returns as compared to early maturing varieties such as 55-437 or ICGS11.

In Benin, farmers have three options per variety, except for the variety 28-206 where farmers had only one choice to apply four sprays. For most, highest returns were attained with four sprays. For examples, for the variety ICGS11, highest returns were attained with four sprays at

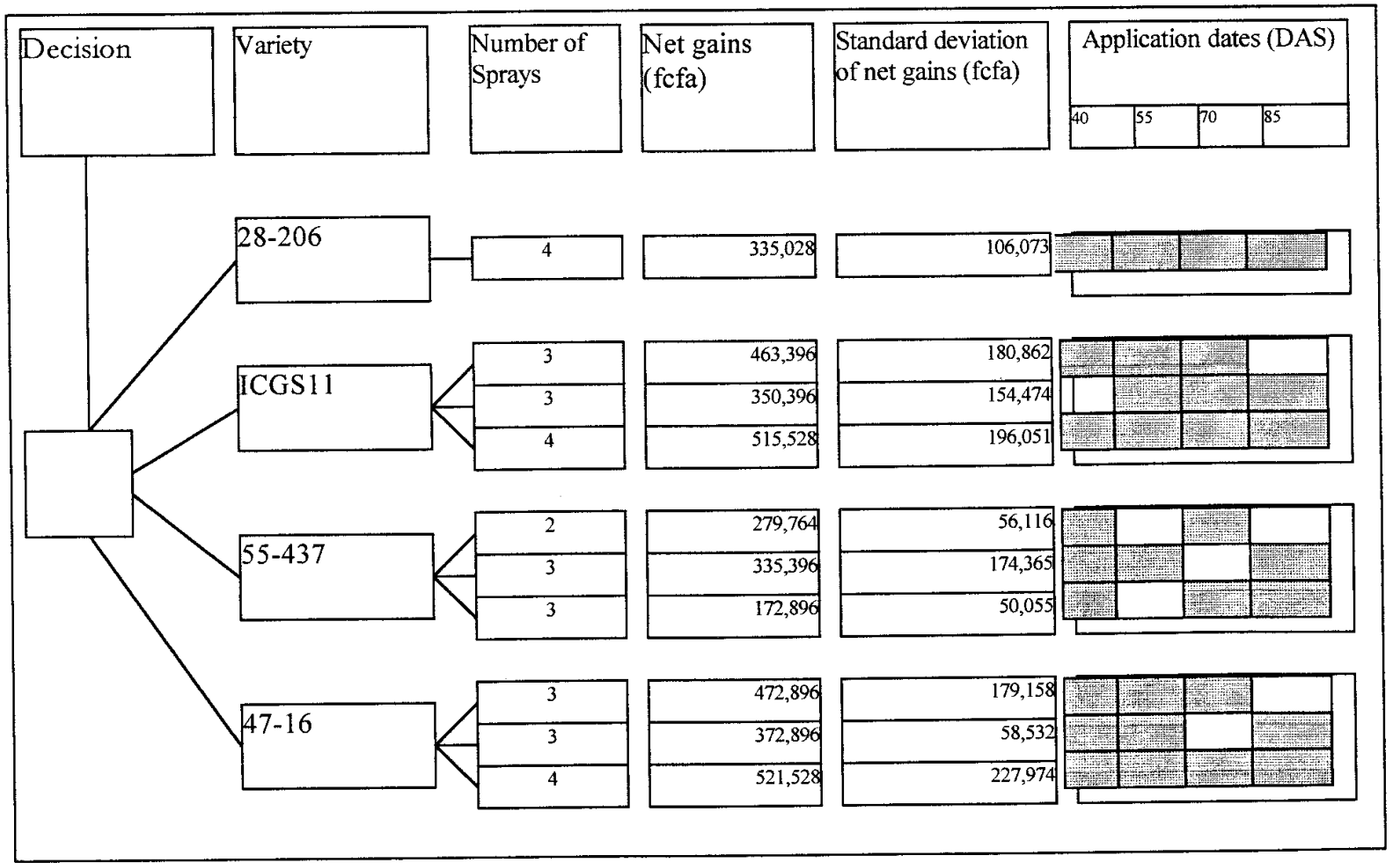

Fig. 4. Decision tree to assist farmers in choosing fungicide application frequencies and dates according to peanut variety in Benin.

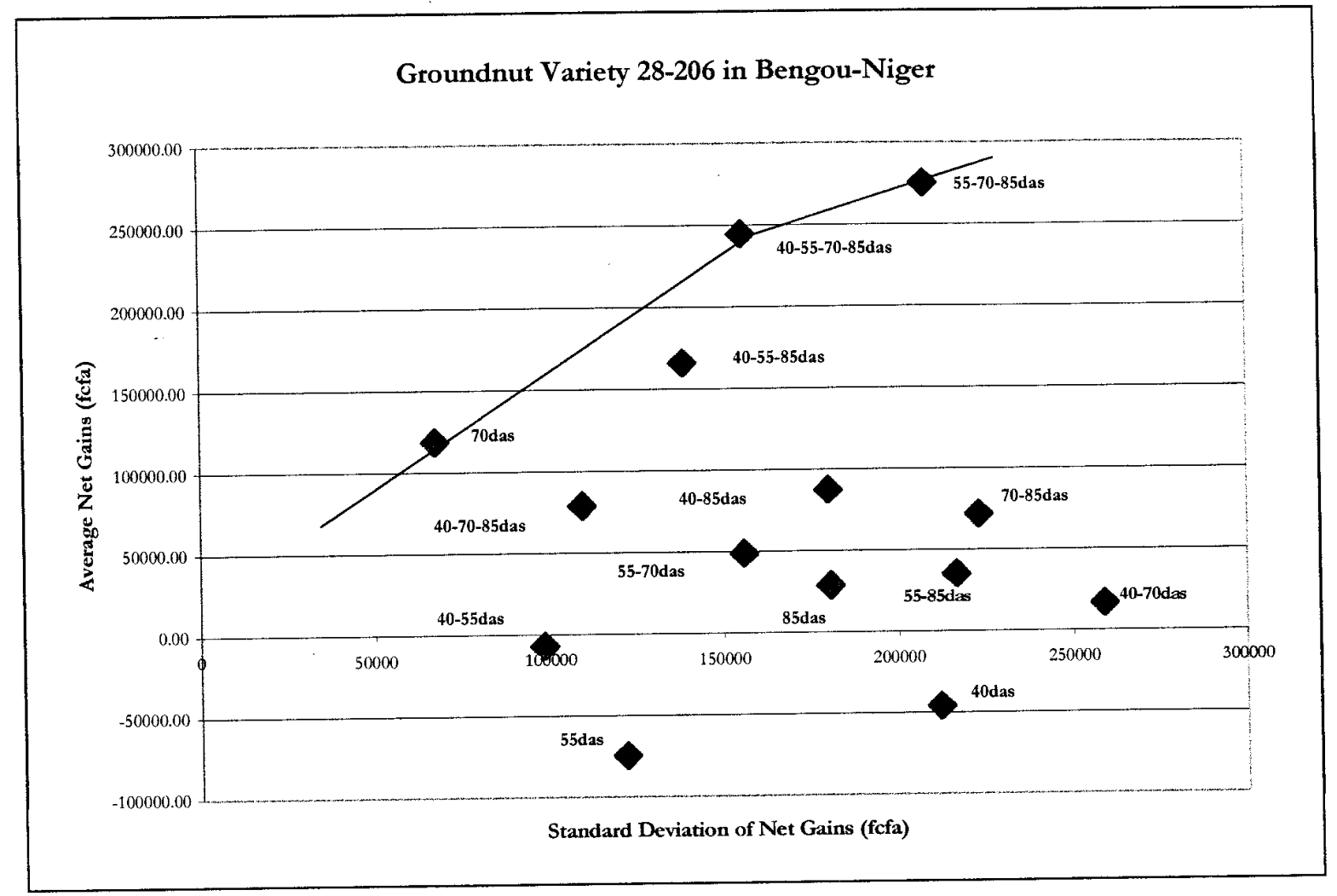

Fig. 5. Mean-standard deviation of net gains of alternative fungicide treatment options for the peanut variety 28-206 in Bengou, Niger. 
515,528 F CFA; and for the variety 47-16, 521,528 F CFA.

In general, the average net gains are higher in Ina, Benin, than in Bengou, Niger, and this is partially due to better rainfall in the former than the latter that allow higher average pod yields. However, the average number of sprays is higher in Be- nin than Niger because of the high incidence of leaf spot disease, particularly in the more humid zone. These options provide farmers with options to manage labor constraints. For example, for variety 55437 in Niger (Fig. 3), farmers may choose not to spray at the 70 DAS, and spray later at 85 days and still attain similar returns.
Similarly, for the variety 28-206, if farmers are severely labor constrained, they may choose just to spray once at 70 DAS and still achieve acceptable returns of 119,132 FCFA per hectare.

Second scenario-Farmers are severely resource constrained and have no access to credit. Decision trees assist
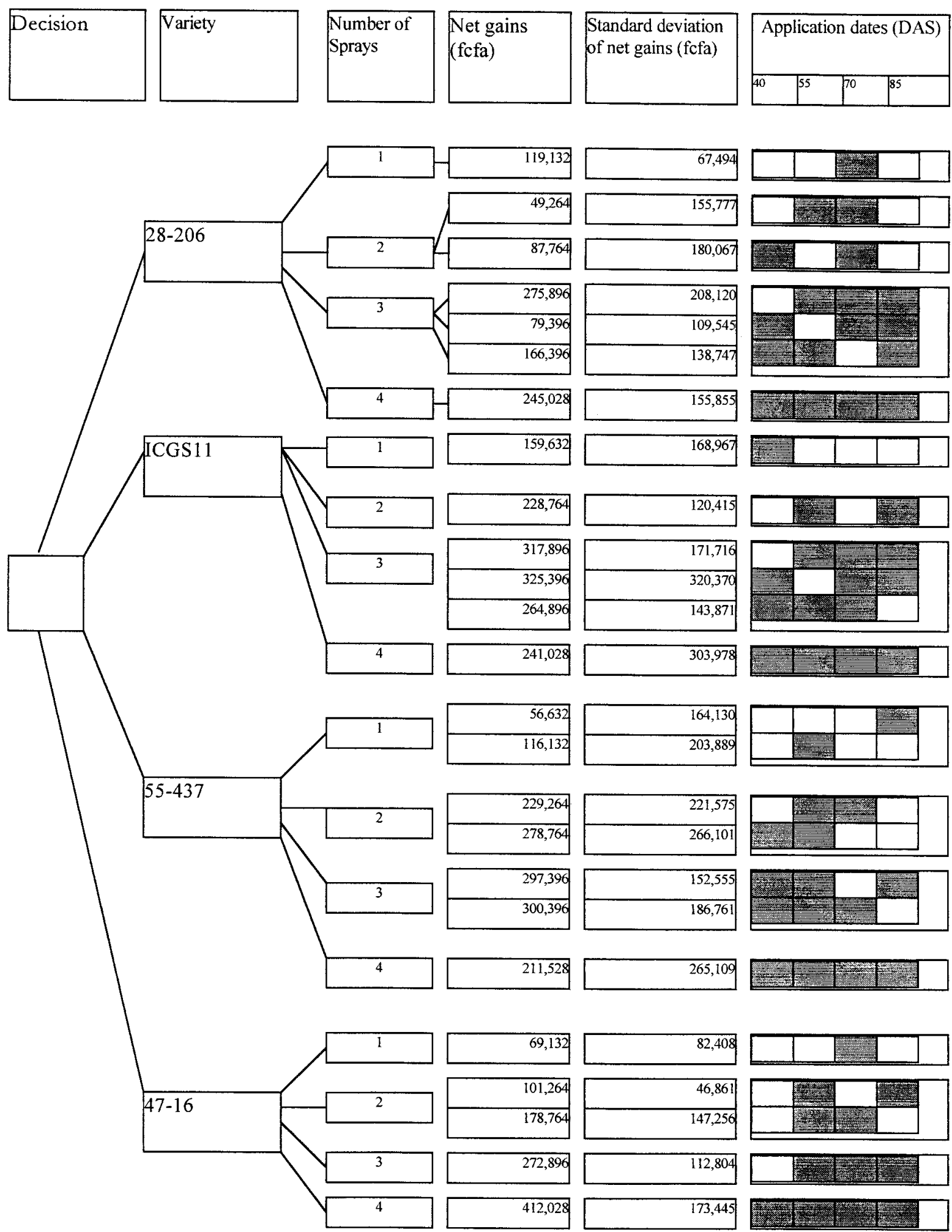

67,494
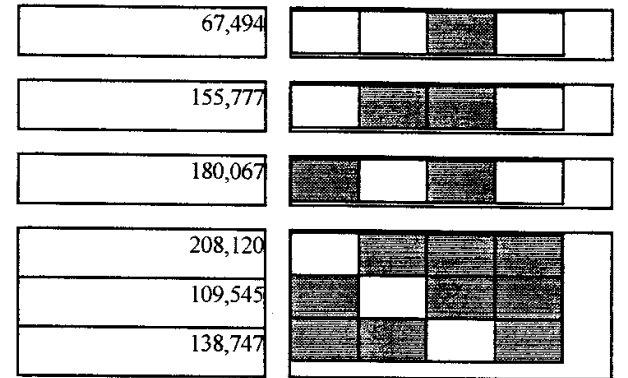

138,74
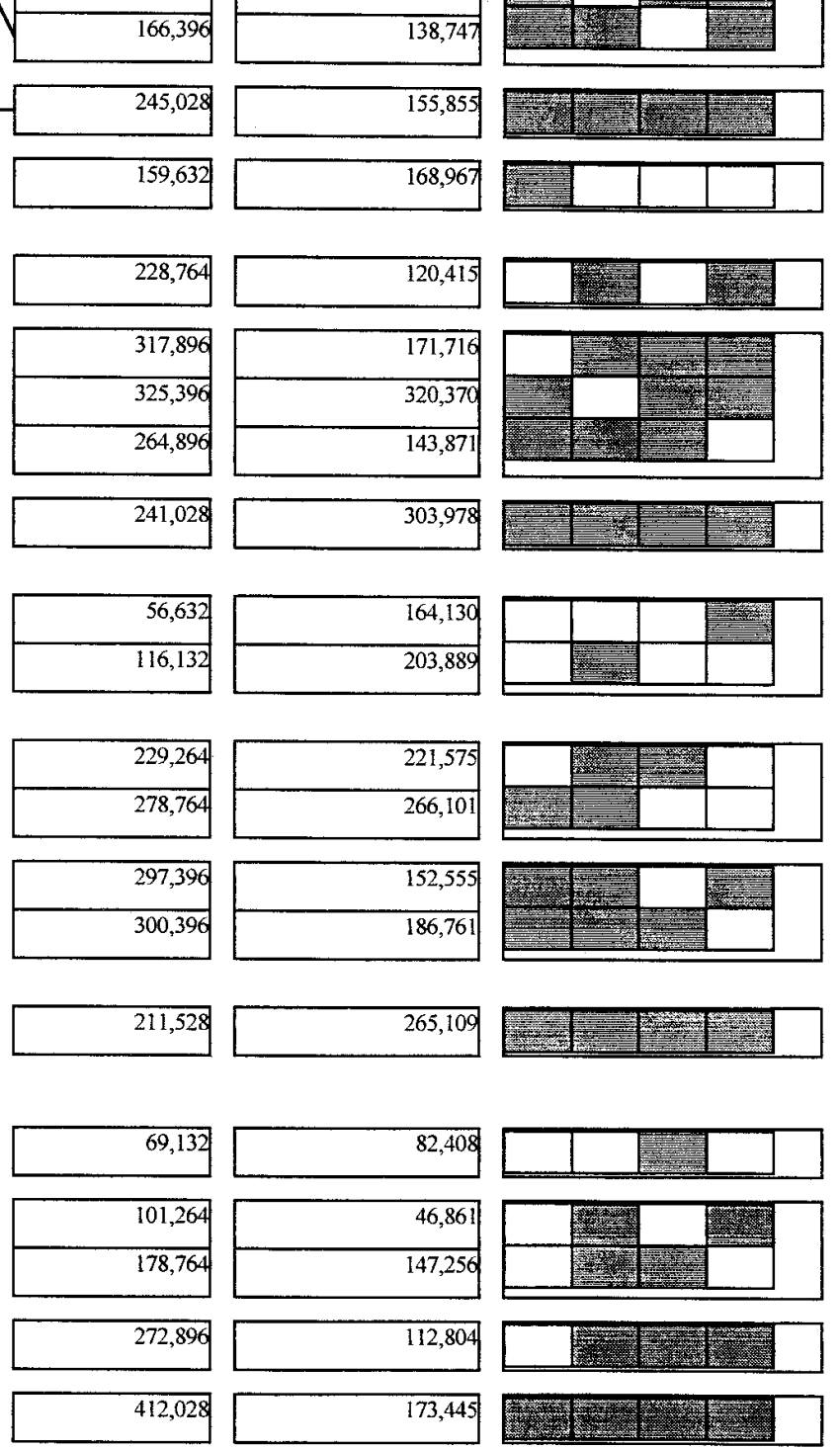

Fig. 6. Decision tree to assist farmers in choosing fungicide application date conditional on the application frequencies and peanut variety in Bengou, Niger. 


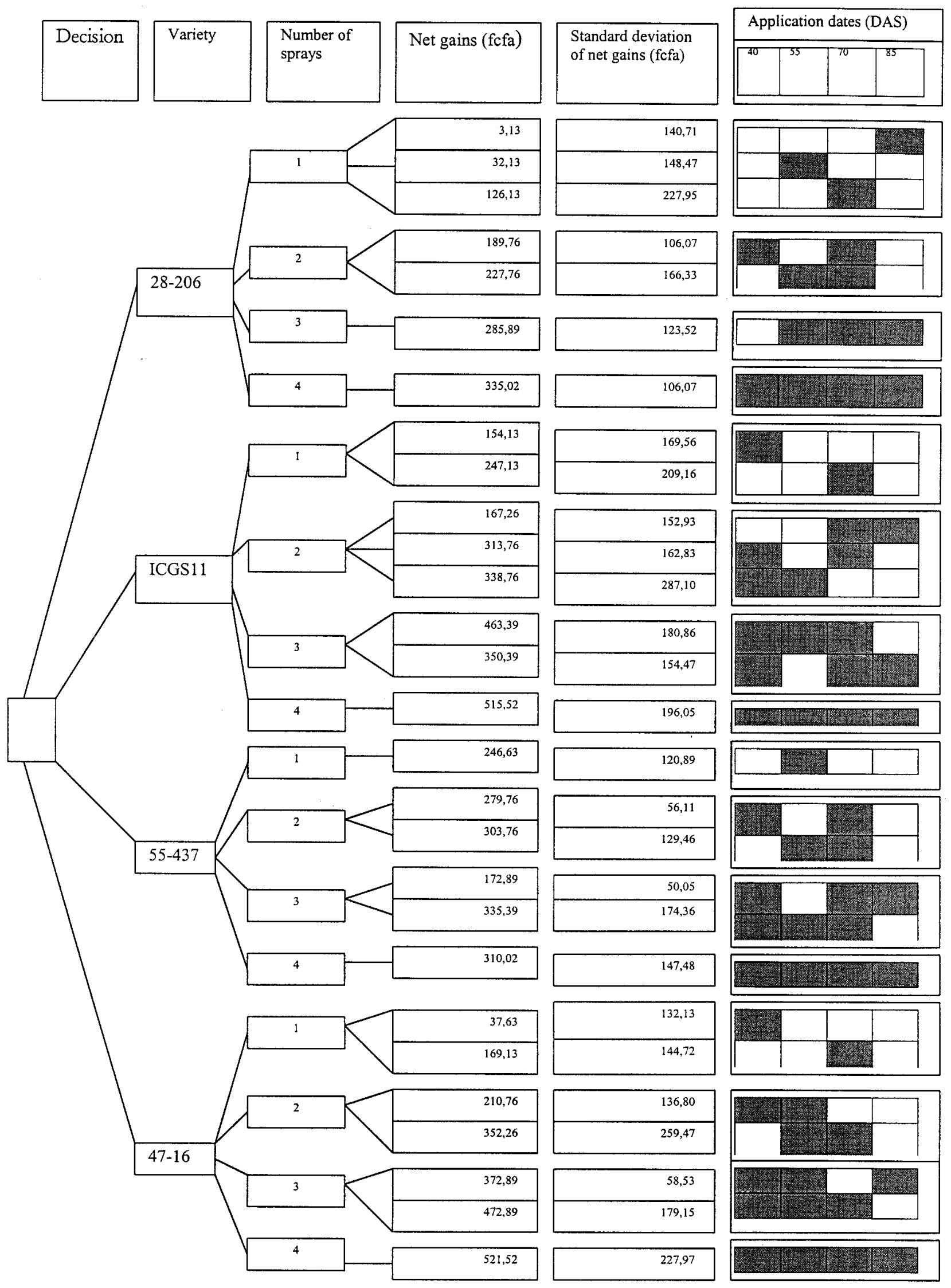

Fig. 7. Decision tree to assist farmers in choosing fungicide application date conditional on the application frequencies and peanut variety in Ina, Benin. 
farmers in choosing better dates of application conditional on the frequency of treatments and variety (Figs. 6 and 7). In Niger, if farmers' resources permit only one fungicide application, spraying once at 70 DAS is best for the late maturing varieties $28-206$ or $47-16$. For the early maturing varieties, ICGS11 and 55-437, the optimal dates of spraying are 40 and 55 DAS, respectively (Fig. 6). Similar findings are reported for the case of Benin (Fig. 7).

\section{DISCUSSION}

Foliar diseases were major constraints to peanut production in both locations. In Benin and Niger, late leaf spot was the most important disease, but progress was much faster at Ina than at Bengou. This is most likely due to climatic differences between the two locations as Ina was wetter than Bengou.

In the past, only a few peanut-producing countries in West Africa used fungicide sprays to control foliar diseases. One of the reasons that fungicides are not used in developing countries is their high cost. Until recently, 8 to 10 fungicide applications were used in some countries to achieve high yields (13). Knowing the economics of fungicide application and the negative impact of fungicides on the environment, many scientists have tried to find ways to reduce fungicide use. Several methods have been used to time fungicide applications; e.g., increasing the interval between sprays by a fixed number of days (every 15 or 21 days), fungicide application according to plant development stage, and use of advisory systems (2,4$6,9,13,17,20,23)$.

The most effective viable system is use of a weather-based advisory developed in the United States to help farmers time fungicide applications $(2,10,14)$. Proper timing of fungicide application reduces the number of applications. In West and Central Africa, many farmers do not have access to modern means of communication, weather monitoring equipment, or expertise that could assist them with the decision to spray. For these reasons, a simple forecaster is needed that can be used by farmers in the region. In the meantime, it is important to provide other approaches that can reduce the effect of foliar diseases on the yield of peanut.

Our work allowed us to measure the impact of a different number and timing of applications and their interactions with cultivars used. Fungicide applications can reduce the amount of diseases and increase pod yield. Several investigators have attempted to develop simplified methods for timing fungicide applications. The most common practice is to apply fungicide at disease onset (16), but if application intervals of 7 to 15 days are used, the number of fungicide applications may vary from six to eight depending on location and length of the rainy season. This high number of fungicide applications is not feasible in developing countries because of cost. Therefore, it is important to identify ways to reduce the number of fungicide applications and still obtain yields that can substantially contribute to the farmer's income. This study shows that correctly timed fungicide sprays can significantly contribute to the economy of farmers in West Africa. The decision trees show that for the four varieties studied, substantial financial gain can be achieved when the farmer is provided with information when to spray. In helping the farmer to determine which sprays are uneconomical, he is able to avoid unnecessary fungicide applications. Similar decision trees can be developed for peanut varieties grown in other parts of West Africa.

There are fungicide treatment options available that could be preferred by farmers adverse to risk and provide significant cash income. Mean-standard deviation dominance comparisons of fungicide treatment options showed that returns to investment could significantly vary by site. Examples provided by this study show that in the more humid area such as Ina, Benin, leaf spot diseases can be severe, requiring farmers to spray on average more frequently than in less humid area such as Bengou, Niger. Despite this high frequency of treatments, the average net gains are higher in Ina, Benin, than Bengou, Niger, due to better soil and climatic conditions.

This study assumed that farmers' activities are centered on peanut production. Farmers in the semi-arid tropics diversify their crops. It would be necessary to assess how these technologies fit farmers overall portfolio of crops. This will permit the choice of fungicides treatments options, which best fit farmers' resource constraints.

\section{LITERATURE CITED}

1. Anderson, J. R., Dillon, J. L., and Hardaker, B. 1980. Agricultural Decision Analysis. The Iowa State University Press, Ames, IA.

2. Bailey, J. E., Johnson, G. L, and Toth, S. J., Jr. 1994. Evolution of a weather-based peanut leaf spot spray advisory in North Carolina. Plant Dis. 78:530-535.

3. Baker, C. B., and Scott, J. 1972. A practical way to select an optimal farm plan under risk. Am. J. Agric. Econ. 54:657-660.

4. Brenneman, T. B., and Culbreath, A. K. 1994. Utilizing a sterol demethylation inhibiting fungicide in an advisory program to manage foliar and soilborne pathogens of peanuts. Plant Dis. 78:866-872.

5. Cu, R. M., and Phipps, P. M. 1993. Development of a pathogen growth response model for the Virginia peanut leaf spot advisory program. Phytopathology 83:195-201.

6. Culbreath, A. K., Brenneman, T. B., and Kvien, C. K. 1992. Use of a resistant peanut cultivar with copper fungicides and reduced fungicide applications for control of late leaf spot. Crop Prot. 11:361-365.

7. Ghuge, S. S., Mayee, C. D., and Godbole, G. M. 1981. Assessment of losses in peanut due to rust and tikka leafspots. Phytopathology 34:179-182.

8. Heady, E. O. 1952. Diversification in resource allocation and minimization of income variability. J. Farm Econ. 34:482-496.

9. Hildebrand, G. L., and Bock, K. R. 1990 Effect of timing of single applications of fungicide on groundnut yield. Pages 3-7 in: Proc. 4th Reg. Groundnut Workshop Southern Africa, Arusha, Tanzania. ICRISAT, Patancheru, Andra Pradesh, India.

10. Johnson, C. S, Phipps, P. M., and Beute, M. K. 1986. Cercospora leafspot management decisions: Uses of a correlation between rainfall and disease severity to evaluate the virginia leaf spot advisory. Phytopathology 76:860-863.

11. Kannaiyan, J., and Haciwa, H. C. 1990. Economic benefits of spraying fungicides to control groundnut foliar disease in Zambia. Trop. Pest Management (United Kingdom) 36:2122.

12. Levy, H., and Markowitz, H. M. 1979. Approximating expected utility by a function of mean variance. Am. Econ. Rev. 69:308-317.

13. Linvill, D. E., and Drye, C. E. 1995. Assessment of peanut leaf spot disease control guidelines using climatological data. Plant Dis. 79:876-879.

14. Matyac, C. A, and Bailey, J. E. 1988. Modification of the peanut leaf spot advisory for use on genotypes with partial resistance. Phytopathology 78:640-644.

15. McDonald, D., Subrahmanyam, P., Gibbons, R. W., and Smith, D. H. 1985. Early and late leafspots of groundnut. International Crops Research Institute for the Semi-Arid Tropics. Inf. Bull. 21. Patancheru, A.P., India.

16. O'Brien, R. G., and Davis, R. D. 1977. Peanut leaf spot and rust control on the Atherton Tableland. Queensl. Agric. J. 103:113-115.

17. Rahman, M. A., Ahmed, H. U., and Alam, K. B. 1986. Studies on the efficacy of fungicides and the date of commencing of spray in controlling tikka and rust of groundnut. Bangl. J. Plant Pathol. 2:57-61.

18. Raya, M. D. 1989. Field control of groundnut foliar disease by fungicides in Tanzania. Proc. Reg. Groundnut Workshop Southern Africa, Lilongwe, Malawi. ICRISAT, Patancheru, A.P., India.

19. Shaner, G., and Finney, R. E. 1977. The effect of nitrogen fertilization on expression of slow mildewing resistance in Knox wheat. Phytopathology 67:1051-1056.

20. Shokes, F. M., Gorbet, D. W., and Sanden, G. E. 1982. Effect of planting date and date of spray initiation on control of peanut leaf spots in Florida (Cercospora arachidicola, Cercosporidium personatum). Plant Dis. 66:574575.

21. Subrahmanyam, P., and Hassan, H. 1990 Response of six groundnut (Arachis hypogaea L.) cultivars to fungicidal control of leaf spots in Niger. Trop. Agric. 67:331-336.

22. Waliyar, F. 1991. Yield losses of groundnut due to foliar diseases in West Africa. Proc. 2nd Reg. Groundnut Workshop, Niamey Niger. ICRISAT, Patancheru, India.

23. Williams, J. H., Ramraj, V. M., and Pal, M. 1984. Physiological studies on foliar diseases (Puccinia arachidis, Phaeoisariopsis personata): Varietal differences in response to use of fungicides. Discussion Group Meeting, Groundnut Rust Disease. Patancheru, A.P., India. 